\title{
Intra-population differences of apolipoproteins in the aqueous humor
}

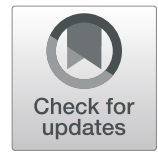

Parth A. Patel', Tae Jin Lee', Sai Karthik Kodeboyina ${ }^{1,2}$, Garrett Jones ${ }^{1}$, Kathryn Bollinger ${ }^{3}$, Lane Ulrich³, David Bogorad ${ }^{3}$, Amy Estes ${ }^{3}$, Wenbo Zhi', Shruti Sharma ${ }^{1,3}$ and Ashok Sharma ${ }^{1,3,4^{*}}$ (D)

\begin{abstract}
Background: Evidence suggests that proteins related to lipid metabolism, such as apolipoproteins, play an important role in the maintenance of normal vision. While several members of the apolipoprotein family are abundant in human aqueous humor (AH), their study remains difficult due to the AH's small volume, low protein concentration, and the invasive nature of sample collection. In this study, we report the use of Liquid Chromatography Tandem Mass Spectrometry (LC-MS/MS) to discover associations between AH apolipoproteins and race, gender, and ocular structure in patients with and without primary open angle glaucoma (POAG).

Methods: AH samples were collected from 231 patients undergoing phacoemulsification or glaucoma incisional surgery at the Medical College of Georgia, Augusta University and subsequently analyzed via LC-MS/MS. The number of peptide spectrum matches (PSMs) for each protein was used as a semi-quantitative measure of relative protein levels. Parameters related to ocular structure were determined using Optical Coherence Tomography (OCT) and Heidelberg Retinal Tomography (HRT). These data sets were probed for relationships between apolipoprotein levels and POAG, demographics (gender and race), and ocular structure.
\end{abstract}

Results: A total of ten apolipoproteins were detected in the 231 collected AH samples, with six detected in 100\% of the samples, one detected in almost $57 \%$ of the samples and three detected in less than $10 \%$ of the samples. The levels of APOA1, APOC3, and APOD were higher among POAG subjects. Stratification by gender and race revealed demographic-specific variations. The levels of five apolipoproteins (APOA1, APOA2, APOA4, APOC3, and APOD) were higher in female POAG patients, whereas no apolipoprotein levels were altered in male POAG patients. The levels of APOA1, APOA2, APOA4, and APOD were increased in glaucomatous African American patients, whereas APOE and APOH levels were decreased in glaucomatous Caucasian patients. We also found distinct associations between apolipoprotein levels and OCT and HRT parameters in patients with and without POAG.

Conclusions: The intra-population variation in apolipoprotein levels highlights the heterogeneity of glaucoma as a disease, suggesting the importance of personalized treatments. Gender and race-specific alterations may be associated with higher risks of POAG in females and members of the African American population.

\footnotetext{
* Correspondence: assharma@augusta.edu

${ }^{1}$ Center for Biotechnology and Genomic Medicine, Medical College of

Georgia, Augusta University, 1120 15th Street, CA4094, Augusta, GA 30912,

USA

${ }^{3}$ Department of Ophthalmology, Medical College of Georgia, Augusta

University, Augusta, GA 30912, USA

Full list of author information is available at the end of the article
}

\section{$\triangle B M C$}

(c) The Author(s). 2021 Open Access This article is licensed under a Creative Commons Attribution 4.0 International License, which permits use, sharing, adaptation, distribution and reproduction in any medium or format, as long as you give appropriate credit to the original author(s) and the source, provide a link to the Creative Commons licence, and indicate if changes were made. The images or other third party material in this article are included in the article's Creative Commons licence, unless indicated otherwise in a credit line to the material. If material is not included in the article's Creative Commons licence and your intended use is not permitted by statutory regulation or exceeds the permitted use, you will need to obtain permission directly from the copyright holder. To view a copy of this licence, visit http://creativecommons.org/licenses/by/4.0/. The Creative Commons Public Domain Dedication waiver (http://creativecommons.org/publicdomain/zero/1.0/) applies to the data made available in this article, unless otherwise stated in a credit line to the data. 


\section{Introduction}

Aqueous humor $(\mathrm{AH})$ is the clear fluid located within the anterior and posterior chambers of the eye. The key functions of $\mathrm{AH}$ include maintenance of refraction, ocular shape, intraocular pressure, oxygen management, nutrient delivery, and metabolic waste removal [1]. To further establish an understanding of these homeostatic processes, research efforts have sought to delineate the $\mathrm{AH}$ proteome [1-4]. Apolipoproteins have been identified as a prominent category in this proteome.

Apolipoproteins carry out many intraocular functions. By binding to lipids, they enable transport of those lipids through various hydrophilic biological domains. When acting as enzymatic cofactors, they are involved in the metabolism of lipoproteins [5, 6]. Through structural and functional complexity, these entities are classified into numerous classes and subclasses, each with a unique role in the complex biological milieu of the human body.

Several studies have examined the relationship between apolipoproteins and ocular conditions including glaucoma, cataracts, pseudo-exfoliation syndrome, and agerelated macular degeneration [7-12]. APOA1, APOC3, and APOE have been shown to be elevated in the $\mathrm{AH}$ of POAG patients as compared to patients with cataracts $[10,12]$. Previous studies have also reported substantial gender-specific differences in plasma apolipoprotein concentrations [13, 14]. However, prior research exploring gender and race variations in the $\mathrm{AH}$ proteome has been limited by relatively small sample sizes [15].

In the present study, we quantified differences in levels of apolipoproteins in 231 subjects based on disease state (POAG vs. non-glaucomatous cataract), gender, race, and ocular structure, as assessed by Heidelberg Retinal Tomography (HRT) and optical coherence tomography (OCT). We found gender and race-specific associations between AH apolipoproteins and POAG. Furthermore, the correlations of apolipoproteins with ocular structure were distinct among the POAG and cataract subgroups.

\section{Materials and methods \\ Subjects}

AH samples were obtained from 231 subjects undergoing ocular surgery at the Medical College of Georgia, Augusta University. Samples were collected by aspiration of $\mathrm{AH}$ from the anterior chamber after the initial clear corneal incision was made during cataract and glaucoma surgeries. This collection does not involve any additional ocular procedures or any alteration in the amount or method of $\mathrm{AH}$ removal. The $\mathrm{AH}$ samples were placed in sealed sterile tubes, then frozen at $-80{ }^{\circ} \mathrm{C}$ until processing. The Institutional Review Board of Augusta University has approved the study (IRB \#611480) and written, informed consents were obtained from all study participants. In total, $158 \mathrm{AH}$ samples from cataract surgery patients and $73 \mathrm{AH}$ samples from POAG patients were collected. No significant differences in race, gender, or IOP levels were observed between these groups (Table 1).

\section{LC-MS/MS analysis}

AH samples $(60 \mu \mathrm{L})$ were successively lyophilized and reconstituted in $30 \mu \mathrm{L}$ of $8 \mathrm{M}$ urea in $50 \mathrm{mM}$ Tris- $\mathrm{HCl}$ ( $\mathrm{pH} 8)$. Cysteine residues were reduced with $20 \mathrm{mM}$ dithiothreitol, alkylated with $55 \mathrm{mM}$ iodoacetemide, followed by the addition of $240 \mu \mathrm{L}$ of $50 \mathrm{mM}$ ammonium bicarbonate buffer to decrease the urea concentration to less than $1 \mathrm{mM}$. Protein concentration was measured using a Bradford assay kit (Pierce, Rockford, IL), according to the manufacturer's instructions. Finally, protein digestion was performed by the addition of a 1:20 ratio $(\mathrm{w} / \mathrm{w})$ of trypsin and maintained overnight at $37 \mathrm{C}^{\circ}$.

The digested $\mathrm{AH}$ samples were cleaned on a C18 spin plate (Nest Group, Southborough, MA, USA), separated via an Ultimate 3000 nano-UPLC system (Thermo Scientific), and analyzed with an Orbitrap Fusion Tribrid mass spectrometer (Thermo Scientific). The reconstituted peptide mixture $(6 \mu \mathrm{L})$ was trapped and washed on a Pepmap100 C18 trap $(5 \mu \mathrm{m}, 0.3 \times 5 \mathrm{~mm})$ for $10 \mathrm{~min}$ at a rate of $20 \mu \mathrm{L} / \mathrm{min}$ using $2 \%$ acetonitrile in water with $0.1 \%$ formic acid. The peptides were then separated on a Pepman100 RSLC C18 column $(2.0 \mu \mathrm{m}, 75 \mu \mathrm{m} \times 150$ $\mathrm{mm}$ ) using a gradient of 2 to $40 \%$ acetonitrile with $0.1 \%$ formic acid over $120 \mathrm{~min}$ (flow rate: $300 \mathrm{~nL} / \mathrm{min}$; column temperature: $40 \quad \mathrm{C}$ ). Eluted peptides were analyzed via data-dependent acquisition in positive mode using the following settings: Orbitrap MS analyzer for precursor scan at 120,000 FWHM from 300 to $1500 \mathrm{~m} / \mathrm{z}$; Ion-trap MS analyzer for MS/MS scans in top speed mode (2-s cycle time) with dynamic exclusion settings (repeat

Table 1 Demographic information of subjects

\begin{tabular}{llll}
\hline Demographic Characteristic & $\begin{array}{l}\text { Cataract } \\
(\boldsymbol{n}=\mathbf{1 5 8 )}\end{array}$ & $\begin{array}{l}\text { POAG } \\
(\boldsymbol{n}=\mathbf{7 3})\end{array}$ & $\boldsymbol{p}$-value \\
\hline Age (years, mean \pm SD) & $67.65 \pm 8.91$ & $68.79 \pm 10.79$ & $0.43^{\mathrm{a}}$ \\
Gender (F/M) & $100 / 58$ & $43 / 30$ & $0.62^{\mathrm{b}}$ \\
Race (African Americans/Caucasians) & $95 / 63$ & $44 / 29$ & $1^{\mathrm{b}}$ \\
\hline
\end{tabular}

atwo-sample t-test

${ }^{\mathrm{b}}$ chi-square test 
count: 1; repeat duration: $15 \mathrm{~s}$; exclusion duration: $30 \mathrm{~s}$ ). The fragmentation method was collision-induced dissociation (CID) with a normalized collision energy of $30 \%$.

\section{Protein identification and quantification}

For the purposes of protein identification and quantification, raw MS data were processed via the Proteome Discoverer (v1.4; Thermo Scientific) and searched using the SequestHT algorithm against the Uniprot-SwissProt human database with 20,385 entries. Search parameters were set as follows: $10 \mathrm{ppm}$ precursor and $0.6 \mathrm{Da}$ product ion tolerances; static carbidomethylation $(+57.021$ Da) for cysteine; dynamic oxidation $(+15.995 \mathrm{Da})$ for methionine; dynamic phosphorylation $(+79.966 \mathrm{Da})$ for serine, threonine, and tyrosine. The Percolator peptidespectrum matching validator located within the Proteome Discoverer software was used to validate PSMs. Proteins unable to be differentiated by MS/MS analysis alone because of similar peptide composition were grouped using the principles of parsimony. The report consisting of identities and spectrum counts (number of PSMs) for each protein was then exported to serve as a semi-quantitative measure of relative protein levels detected in each $\mathrm{AH}$ sample.

\section{OCT and HRT measurements}

Retinal nerve fiber layer (RNFL) thickness was calculated using SPECTRALIS Tracking Laser Tomography (Heidelberg Engineering, Franklin, MA, USA). Via this system, a 24-line high resolution radial scan of the optic nerve head centered on the Bruch's membrane opening (BMO) was acquired. The neuroretinal rim was subsequently defined as the region between the BMO and the nearest point on the internal limiting membrane based on this image. RNFL thickness was determined utilizing three circular scans centered on the optic nerve head delineated by the BMO. These findings were then compared to a reference database of healthy eyes adjusted for $\mathrm{BMO}$ size and age and presented in the GarwayHeath sector format, facilitating structural and functional correlations. Additionally, the ganglion cell layer (GCL) and the macula were comprehensively evaluated by the multi-layer segmentation software, the results of which were illustrated using a GCL thickness map.

Imaging of the optic nerve head was also performed using the Heidelberg Retinal Tomograph (Heidelberg Engineering, Franklin, MA, USA). A set of 3D images of the optic nerve and surrounding retina at various depths were collected and collated to create a 3D representation of the whole optic nerve. From this, a set of stereometric parameters (e.g., cup-to-disc area ratio, cup shape measure, and rim volume) were calculated. The cup-to-disc area ratio evaluates the extent of cupping relative to the area of the optic disc. In patients with uncontrolled glaucoma, the cup-to-disc area increases over time. The cup shape measure numerically encapsulates the configuration of the cup, incorporating an assessment of both the steepness of cup walls and variation in depth. In patients without evidence of glaucomatous damage, this metric is generally negative. Conversely, for glaucomatous eyes, this value is typically less negative or positive [16]. Finally, rim area assesses the neuroretinal rim, which forms the demarcation between the cup and disc. Among patients with glaucoma, this metric is typically lower, reflecting degradation or loss of the nerve fibers that compose the neuroretinal rim.

\section{Statistical analyses}

All statistical analyses were performed using the R project for Statistical Computing (version 3.6.3). The twotailed t-test and chi-square tests were utilized to compare the clinical characteristics of POAG and cataract patients. Prior to data analysis, PSM values derived from LC-MS/MS analysis were quantile normalized and the proportion of samples in which each protein was detected was determined. The negative binomial regression model was fitted to assess the disease-specific differences in apolipoproteins levels. Correlations between apolipoproteins and clinical parameters (e.g., OCT and HRT measures) were assessed through Spearman's correlation coefficients. The threshold for significance was set at $p<0.05$.

\section{Results}

\section{Apolipoprotein levels in human aqueous humor}

A total of 21 apolipoproteins are known to be a part of the human proteome [17], 10 of which we identified in the $231 \mathrm{AH}$ samples analyzed (Fig. 1). The mean PSM values of all apolipoproteins and the proportion of samples in which they were detected are listed in Table 2 . Three of the 10 apolipoproteins were detected in fewer than $10 \%$ of samples and were therefore excluded from further statistical analyses. Six of the other seven apolipoproteins were detected in $100 \%$ of samples, while the seventh was detected in $57 \%$ of our samples. These seven most abundant apolipoproteins were APOA1 (mean PSM $\pm \mathrm{SD}, 102.88 \pm 44.25)$, APOH $(61.44 \pm 21.30$ ), APOA4 (34.88 \pm 23.25$)$, APOE $(28.82 \pm 11.41)$, APOA2 $(26.36 \pm 14.09), \quad$ APOD $(10.62 \pm 5.10), \quad$ and APOC3 $(3.63 \pm 2.80)$.

\section{POAG-specific alterations in human aqueous humor apolipoproteins}

Statistical analyses were performed to determine the POAG-specific alterations in aqueous humor apolipoproteins using all 231 samples (Fig. 2). Fold change (FC) values represent the change in protein levels in the POAG group $(n=158)$ compared to the cataract group $(n=73)$. The levels of three proteins, APOA1 $(\mathrm{FC}=1.17$; 


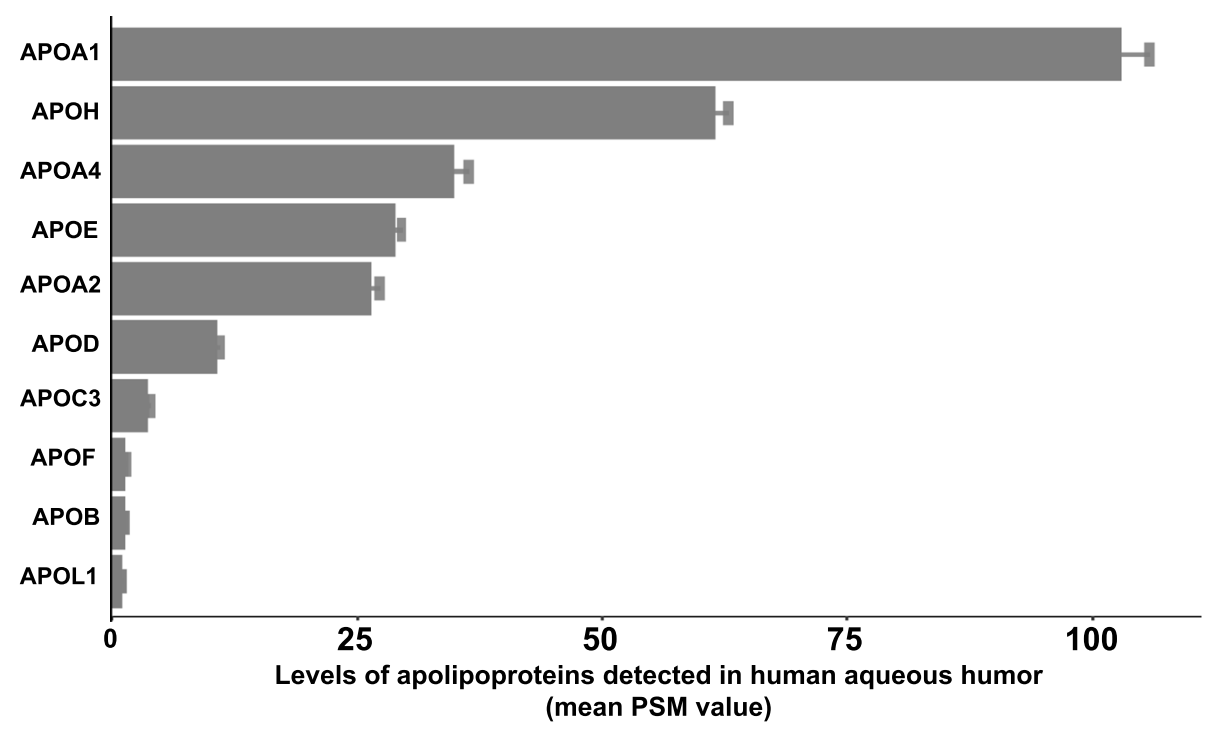

Fig. 1 Levels of the ten apolipoproteins detected in 231 human aqueous humor samples

$p=0.01)$, APOC3 (FC $=1.25 ; p=0.02)$, and APOD $(\mathrm{FC}=$ $1.13 ; p=0.04)$, were significantly higher in POAG patients as compared to cataract patients (Table 3).

Demographic variation in these apolipoproteins was investigated by further stratification of our subjects according to gender and race. Within the male subset, no significant differences in apolipoprotein levels were found between POAG and cataract subjects. Conversely, female POAG patients had significantly greater levels of APOA1 $(\mathrm{FC}=1.36 ; p<0.01)$, APOA2 $(\mathrm{FC}=1.21 ; p=$

Table 2 Levels of apolipoproteins in human aqueous humor

\begin{tabular}{|c|c|c|c|}
\hline Gene Symbol & Description & Mean PSM Value $( \pm$ SD) & Detected in Proportion of Samples (\%) \\
\hline APOA1 & Apolipoprotein A-I & $102.88 \pm 44.25$ & 100 \\
\hline $\mathrm{APOH}$ & Beta-2-glycoprotein 1 & $61.44 \pm 21.30$ & 100 \\
\hline APOA4 & Apolipoprotein A-IV & $34.88 \pm 23.25$ & 100 \\
\hline APOE & Apolipoprotein E & $28.82 \pm 11.41$ & 100 \\
\hline APOA2 & Apolipoprotein A-II & $26.36 \pm 14.09$ & 100 \\
\hline APOD & Apolipoprotein D & $10.62 \pm 5.10$ & 100 \\
\hline APOC3 & Apolipoprotein C-III & $3.63 \pm 2.80$ & 57.14 \\
\hline APOF & Apolipoprotein F & $1.29 \pm 0.51$ & 7.36 \\
\hline APOB & Apolipoprotein B-100 & $1.23 \pm 0.53$ & 8.23 \\
\hline APOL1 & Apolipoprotein L1 & $1.05 \pm 0.1$ & 5.63 \\
\hline APOA5 & Apolipoprotein A-V & ND & 0 \\
\hline APOC1 & Apolipoprotein C-I & ND & 0 \\
\hline APOC2 & Apolipoprotein C-II & ND & 0 \\
\hline APOC4 & Apolipoprotein C-IV & ND & 0 \\
\hline APOL2 & Apolipoprotein L-II & ND & 0 \\
\hline APOL3 & Apolipoprotein L-III & ND & 0 \\
\hline APOL4 & Apolipoprotein L-IV & ND & 0 \\
\hline APOL5 & Apolipoprotein L-V & ND & 0 \\
\hline APOL6 & Apolipoprotein L-VI & ND & 0 \\
\hline APOM & Apolipoprotein M & ND & 0 \\
\hline APOO & Apolipoprotein O & ND & 0 \\
\hline
\end{tabular}




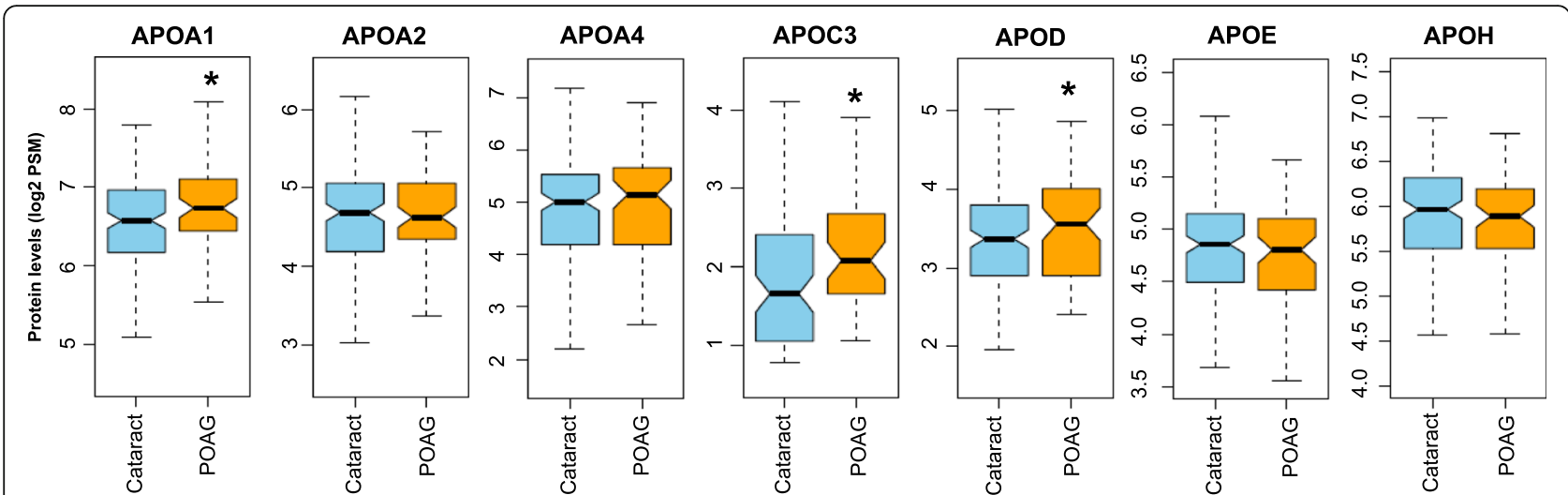

Fig. 2 Levels of three apolipoproteins were significantly increased in subjects with primary open angle glaucoma (POAG) compared to subjects with cataracts alone, the controls (C). The boxplots depict the distribution of protein levels in each group. Peptide spectrum match (PSM) values were used as semi-quantitative measurement of protein levels. The raw PSM values were log2 transformed to achieve a normal distribution

$0.03)$, APOA4 $(\mathrm{FC}=1.30 ; p=0.04)$, APOC3 $(\mathrm{FC}=1.38$ $p=0.01)$, and APOD (FC $=1.20 ; p=0.04)$ compared to cataract patients (Fig. 3).

When parsed along the lines of race, two apolipoprotein levels were found to be lower in the Caucasian POAG subset: APOE $(\mathrm{FC}=0.82 ; p=0.02)$ and $\mathrm{APOH}$ $(\mathrm{FC}=0.76 ; p=0.01)$. In the African American POAG subset, significant upregulation of four apolipoproteins was noted: APOA1 $(\mathrm{FC}=1.34 ; p<0.01)$, APOA2 $(\mathrm{FC}=$ $1.25 ; p=0.02)$, APOA4 $(\mathrm{FC}=1.37 ; p=0.01)$, and APOD $(\mathrm{FC}=1.19 ; p=0.04)($ Fig. 4).

\section{Correlation of human aqueous humor apolipoproteins with RNFL thickness}

Two of the seven apolipoproteins were significantly correlated with RNFL thickness across the 231 subjects: APOC3 $(\rho=-0.25 ; p=0.01)$ and APOD $(\rho=-0.31 ; p<$ 0.01 . When these subjects were stratified by disease state, only the association between APOD levels and RNFL thickness remained significant in the POAG subset $(\rho=-0.44 ; p<0.01)$.
Correlation of human aqueous humor apolipoproteins with HRT parameters

The association of the seven apolipoproteins with HRT parameters are recorded in Table 4. APOC3 levels were positively correlated with cup shape measure $(\rho=0.37$; $p=0.01)$, which persisted in the cataract subset $(\rho=0.39$; $p=0.01)$. Contrastingly, amongst the POAG subgroup, levels of APOA1 $(\rho=-0.51 ; p<0.01)$, APOA2 $(\rho=-$ $0.49 ; p<0.01)$, and APOH $(\rho=-0.61 ; p<0.01)$ had a negative correlation with cup shape measure.

The cup-to-disc ratio was negatively associated with APOE $(\rho=-0.32 ; p<0.01)$ and APOH $(\rho=-0.21 ; p=$ $0.02)$ in the overall sample set. This negative correlation persisted for APOE in the cataract subset $(\rho=-0.32$; $p<0.01)$ and APOH in the POAG subset $(\rho=-0.37$; $p=0.02$ ).

Rim volume was negatively associated with APOC3 level $(\rho=-0.29 ; p=0.02)$, but positively associated with APOE $(\rho=0.27 ; p<0.01)$. Stratification by POAG and cataract status only retained the positive correlation between APOE and rim volume in the cataract subset ( $\rho=$ 0.36; $p<0.01)$.

Table 3 Race and sex specific changes in the levels of apolipoproteins in POAG subjects

\begin{tabular}{|c|c|c|c|c|c|c|c|c|}
\hline & & $\begin{array}{l}\text { APOA1 } \\
(\text { Mean } \mathrm{PSM} \pm \mathrm{SD})\end{array}$ & $\begin{array}{l}\text { APOA2 } \\
(\text { Mean PSM } \pm \text { SD) }\end{array}$ & $\begin{array}{l}\text { APOA4 } \\
(\text { Mean PSM } \pm \text { SD) }\end{array}$ & $\begin{array}{l}\text { APOC3 } \\
(\text { Mean PSM } \pm \text { SD) }\end{array}$ & $\begin{array}{l}\text { APOD } \\
(\text { Mean } \mathrm{PSM} \pm \mathrm{SD})\end{array}$ & $\begin{array}{l}\text { APOE } \\
(\text { Mean } \mathrm{PSM} \pm \mathrm{SD})\end{array}$ & $\begin{array}{l}\text { APOH } \\
(\text { Mean } \mathrm{PSM} \pm \mathrm{SD} \text { ) }\end{array}$ \\
\hline \multirow[t]{2}{*}{ Overall } & Cataract & $97.29 \pm 39.78$ & $25.44 \pm 12.16$ & $33.94 \pm 23.69$ & $3.3 \pm 2.79$ & $10.09 \pm 4.74$ & $29.15 \pm 10.79$ & $62.39 \pm 21.26$ \\
\hline & POAG & $114.97 \pm 50.87^{*}$ & $28.34 \pm 17.49$ & $36.91 \pm 22.31$ & $4.21 \pm 2.77^{*}$ & $11.75 \pm 5.67^{*}$ & $28.08 \pm 12.68$ & $59.4 \pm 21.4$ \\
\hline \multirow[t]{2}{*}{ Male } & Cataract & $111.95 \pm 39.55$ & $29.03 \pm 14.01$ & $42.26 \pm 23.82$ & $3.79 \pm 2.78$ & $10.14 \pm 3.96$ & $28.32 \pm 9.69$ & $67.47 \pm 21.46$ \\
\hline & POAG & $107.84 \pm 44.59$ & $26.64 \pm 11.7$ & $38.47 \pm 20.76$ & $3.96 \pm 2.49$ & $10.9 \pm 5.11$ & $26.69 \pm 10.23$ & $58.3 \pm 23.67$ \\
\hline \multirow[t]{2}{*}{ Female } & Cataract & $88.79 \pm 37.56$ & $23.36 \pm 10.46$ & $29.11 \pm 22.34$ & $2.97 \pm 2.77$ & $10.07 \pm 5.16$ & $29.64 \pm 11.4$ & $59.44 \pm 20.68$ \\
\hline & POAG & $119.94 \pm 54.78^{*}$ & $29.52 \pm 20.65^{*}$ & $35.82 \pm 23.5^{*}$ & $4.35 \pm 2.96^{*}$ & $12.34 \pm 6.01^{*}$ & $29.05 \pm 14.18$ & $60.16 \pm 19.93$ \\
\hline \multirow[t]{2}{*}{ Caucasian } & Cataract & $113.2 \pm 36.86$ & $30.57 \pm 11.98$ & $42.15 \pm 23.49$ & $3.01 \pm 2.3$ & $10.16 \pm 4.74$ & $30.75 \pm 11.32$ & $71.39 \pm 20.65$ \\
\hline & POAG & $112.58 \pm 43.7$ & $27.75 \pm 11.8$ & $39.24 \pm 25.54$ & $3.92 \pm 2.15$ & $10.63 \pm 4.79$ & $25.03 \pm 9.09^{*}$ & $56.8 \pm 24.06^{*}$ \\
\hline \multirow{2}{*}{$\begin{array}{l}\text { African } \\
\text { American }\end{array}$} & Cataract & $86.74 \pm 38.27$ & $22.04 \pm 11.08$ & $28.49 \pm 22.32$ & $3.44 \pm 3.01$ & $10.05 \pm 4.77$ & $28.09 \pm 10.35$ & $56.42 \pm 19.58$ \\
\hline & POAG & $116.54 \pm 55.52^{*}$ & $28.72 \pm 20.52^{*}$ & $35.37 \pm 20.06^{*}$ & $4.36 \pm 3.08$ & $12.49 \pm 6.12^{*}$ & $30.1 \pm 14.32$ & $61.11 \pm 19.56$ \\
\hline
\end{tabular}



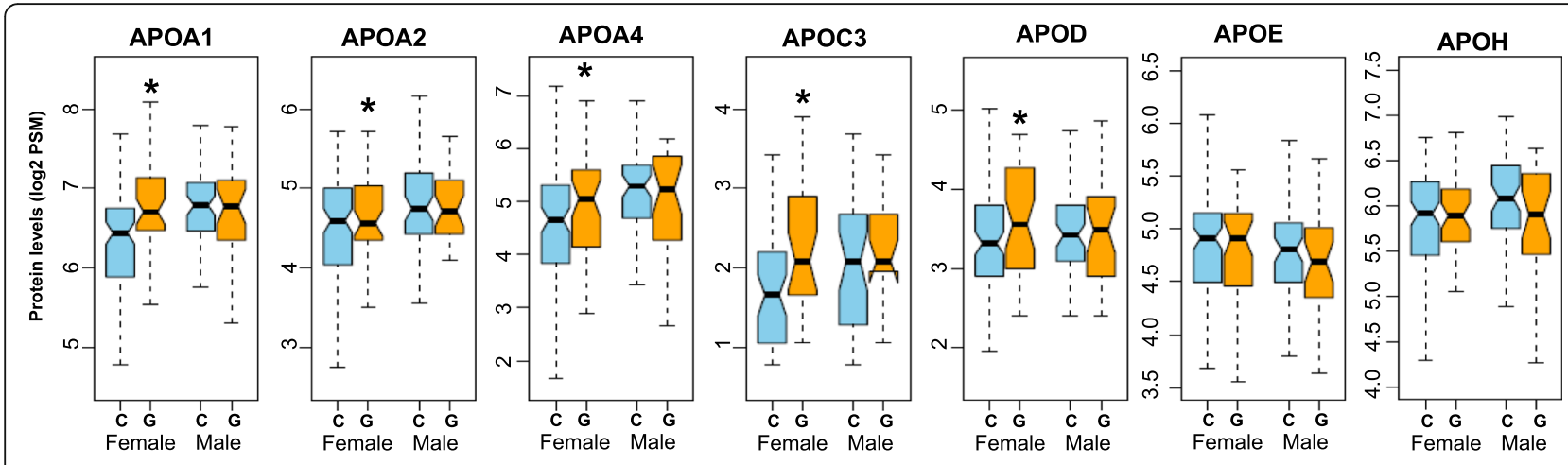

\section{C: Cataract}

G: POAG

Fig. 3 Levels of five apolipoproteins were significantly increased in female subjects with primary open angle glaucoma (G) compared to subjects with cataracts alone, the controls (C). No significant alterations in apolipoproteins were detected in male subjects. The boxplots depict the distribution of protein levels in each group

\section{Discussion}

Examination of variations in the $\mathrm{AH}$ proteome between disease states as well as between demographic groups may prove helpful in understanding the elusive mechanism(s) of glaucomatous optic neuropathy. Apolipoproteins have been previously established as markers for multiple systemic [18-20] and neurodegenerative diseases [21-25], and it has been more recently observed that their levels in $\mathrm{AH}$ are altered in the presence of ocular conditions $[8,10]$. As such, we aimed to probe our large data set for differences in $\mathrm{AH}$ apolipoprotein levels between glaucomatous and cataract patients and quantify intra-population variation. In both of these areas, we discovered interactive effects that suggest disease-specific alterations in apolipoprotein levels vary between demographic groups.

We detected 10 apolipoproteins in our $\mathrm{AH}$ samples. After excluding the three low-incidence apolipoproteins
(APOB, APOF, APOL1), the remaining seven (APOA1, APOA2, APOA4, APOC3, APOD, APOE, and APOH) were abundant in the $\mathrm{AH}$ proteome. The detection of APOA1, APOA2, APOA4, APOD, APOE, and APOH is consistent with the findings of other studies $[3,12,26]$.

When considering all 231 subjects, APOA1, APOC3, and APOD were significantly higher among patients with POAG. This agrees with previous investigations wherein elevated levels of both APOA1 and APOC3 were detected among individuals with glaucoma [12, 27]. APOA1 levels, in particular, have demonstrated potential value for the detection of primary chronic angle-closure glaucoma as the component of a proposed diagnostic protein panel [28]. Leveraging such a finding to therapeutic effect remains difficult as mechanistic linkages to the optic neuropathy remain to be discovered. Investigations of other ocular conditions (e.g., diabetic retinopathy, age-related maculopathy) have posited that
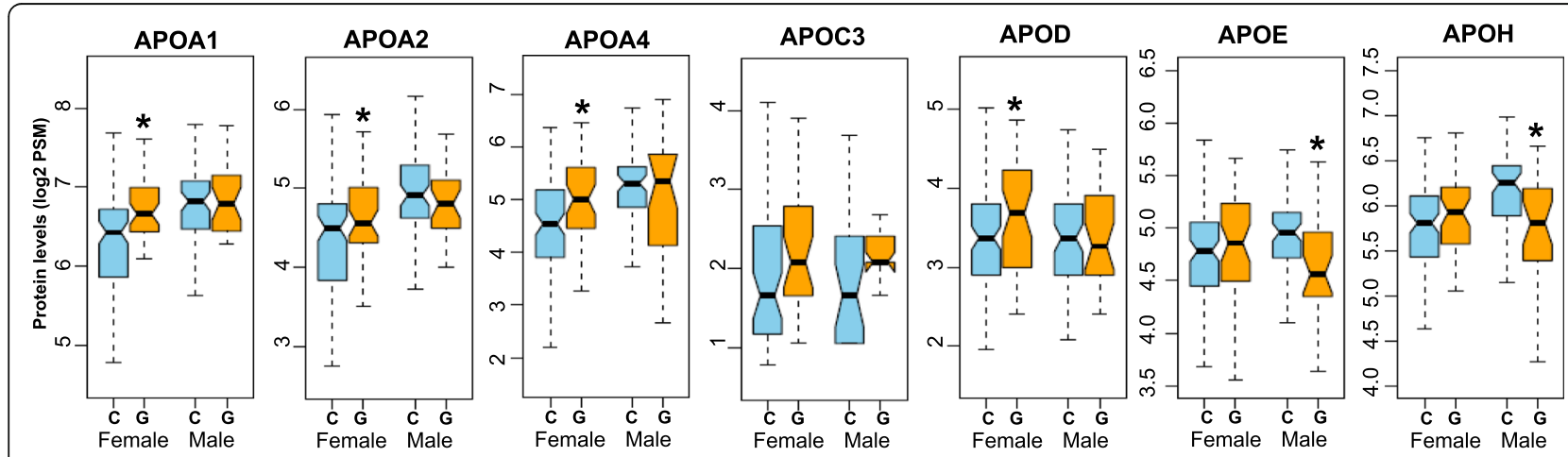

\section{C: Cataract}

G: POAG

Fig. 4 Levels of four apolipoproteins were significantly increased in African American subjects with primary open angle glaucoma (G) compared to subjects with cataracts alone, the controls (C). Levels of two apolipoproteins were significantly decreased in Caucasian subjects with primary open angle glaucoma compared to subjects with cataracts alone. The boxplots depict the distribution of protein levels in each group 
Table 4 Apolipoproteins significantly correlated with clinical parameters

\begin{tabular}{|c|c|c|c|c|c|c|c|}
\hline \multirow[t]{2}{*}{ Proteins } & \multirow[t]{2}{*}{ Clinical Variables } & \multicolumn{2}{|c|}{ Overall } & \multicolumn{2}{|c|}{ Cataract } & \multicolumn{2}{|l|}{ POAG } \\
\hline & & Corr. & $P$-value & Corr. & $P$-value & Corr. & $P$-value \\
\hline \multicolumn{8}{|c|}{ OCT Parameters } \\
\hline APOC3 & RNFL avg. thickness & -0.25 & $0.01^{*}$ & -0.25 & 0.06 & -0.22 & 0.20 \\
\hline APOD & RNFL avg. thickness & -0.31 & $<0.01^{*}$ & 0.00 & 0.99 & -0.44 & $<0.01^{*}$ \\
\hline \multicolumn{8}{|c|}{ HRT Parameters } \\
\hline APOA1 & Cup Shape Measure & 0.00 & 0.98 & 0.19 & 0.09 & -0.51 & $<0.01^{*}$ \\
\hline APOA2 & Cup Shape Measure & -0.03 & 0.74 & 0.15 & 0.18 & -0.49 & $0.01^{*}$ \\
\hline APOC3 & Cup Shape Measure & 0.37 & $0.01^{*}$ & 0.39 & $0.01^{*}$ & 0.39 & 0.17 \\
\hline $\mathrm{APOH}$ & Cup Shape Measure & -0.07 & 0.45 & 0.18 & 0.10 & -0.61 & $<0.01^{*}$ \\
\hline APOC3 & Rim Volume $\left(\mathrm{mm}^{2}\right)$ & -0.29 & $0.02^{*}$ & -0.25 & 0.12 & -0.27 & 0.24 \\
\hline APOE & Rim Volume $\left(\mathrm{mm}^{2}\right)$ & 0.27 & $<0.01^{*}$ & 0.36 & $<0.01^{*}$ & 0.17 & 0.31 \\
\hline APOE & Cup to Disc Area ratio & -0.19 & $0.04^{*}$ & -0.32 & $<0.01^{*}$ & -0.08 & 0.63 \\
\hline $\mathrm{APOH}$ & Cup to Disc Area ratio & -0.21 & $0.02^{*}$ & -0.03 & 0.77 & -0.37 & $0.02^{*}$ \\
\hline
\end{tabular}

Corr. Correlation coefficient

increased APOA1 levels may indicate underlying inflammatory processes $[29,30]$. Although there is a robust corpus of literature that implicates neuro-inflammation in glaucomatous optic neuropathy [31], further research is needed to elucidate pathophysiologic connections.

Overall, only three apolipoproteins were significantly higher among glaucomatous patients. However, these findings were different in male and female subgroups, suggesting an interactive effect between disease state, gender, and apolipoprotein levels. No apolipoprotein levels were found to be altered in males based on disease state, while five apolipoprotein (APOA1, APOA2, APOA4, APOC3, and APOD) levels were increased in females with POAG. Several studies have previously detected significant gender-specific differences in systemic (serum) apolipoprotein levels [13, 14, 32]. Schaefer et. al. observed an elevated plasma level of APOA1 among females $(124 \pm 24 \mathrm{mg} / \mathrm{dl})$ relative to males $(108 \pm 16 \mathrm{mg} / \mathrm{dl})$ [13]. A more recent investigation by Anagnostis et. al. reported similar findings and further identified an interaction between menopause status, age, and plasma concentrations of APOA1, APOA2, and APOB in females [14]. However, heretofore, limited research has extended into human AH. Perumal et. al. reported genderdependent changes in the $\mathrm{AH}$ proteome [15]. The present investigation extends such findings by suggesting gender-specific differences in POAG. Further research is required to delineate whether such findings distill along structural, endocrine or other lines. Support for the structural vantage point comes from reports indicating females as having average shorter axial lengths and shallower anterior chamber depths [33-36]. Support for the endocrine aspect comes from reports proposing a protective effect of endogenous estrogen for retinal ganglion cells in pre-menopausal females [37]. The authors suggested mechanisms relating to extracellular matrix production and cellular signaling [38-40]. Regardless, further characterization of pathophysiologic differences between the genders and POAG is necessary to explain the variance in apolipoprotein levels.

We also observed interactions between race and $\mathrm{AH}$ apolipoprotein levels. Within the African American cohort, APOA1, APOA2, APOA4, and APOD levels were significantly higher among glaucoma patients. Alternatively, the Caucasian glaucomatous cohort had lower levels of APOE and APOH. These findings pose multiple questions. First, does this divergence explain on some level the increased incidence, progression, and severity of glaucoma in the African American population [41, 42]? Second, does race predict different disease patterns and treatment responses? If so, analyses with specific racial compositions of patients may be necessary for personalized treatment algorithms. Third, while prior investigations have reported increased levels of APOE among glaucomatous subjects [12,43], our study did not confirm this. Instead, we found APOE levels decreased among glaucomatous patients only within the Caucasian subset. Accordingly, it is important for future studies characterizing the $\mathrm{AH}$ proteome to further investigate the impact of race on the $\mathrm{AH}$ proteome when interpreting findings to reduce this as a potential confounding factor.

Assessment of the relationship between OCT parameters and $\mathrm{AH}$ apolipoprotein levels demonstrated a negative correlation between average RNFL thickness and two apolipoproteins (APOC3 and APOD). However, this association only persisted with APOD amongst the glaucoma subset. Interestingly, this is the same apolipoprotein which has emerged as a potential candidate for evaluation in pseudoexfoliative glaucoma and the 
neurodegenerative conditions of multiple sclerosis and Alzheimer's disease [44-48]. Among glaucomatous patients, APOD has previously been demonstrated to correlate with functional visual field parameters including Pattern Standard Deviation (PSD), Visual Field Index (VFI), Mean Deviation (MD), and Glaucoma Hemifield Test (GHT) [49]. Lipids and cholesterol are conserved following neurodegenerative processes [50, 51], and therefore elevated APOD levels may reflect increased recycling of these substances during regeneration. This, in turn, may promote neuritogenesis and synaptogenesis in these patients [52]. Taken together, these results suggest that higher levels of APOD may facilitate increased regeneration in patients with glaucomatous damage.

Previously, APOC3 has been implicated in certain ocular conditions. Increased APOC3 levels have been observed in patients with branch retinal vein occlusion with macular edema. It is proposed as interrelating with inflammatory processes [53]. Other studies have also elucidated a linkage between POAG and APOC3 [10, 27, 54]. In these studies, APOC3 levels were also upregulated. Although APOH was associated with HRT parameters in POAG patients, there remains a limited understanding of its role within the neurodegenerative condition. Despite its implication in other ocular diseases such as proliferative diabetic retinopathy $[55,56]$, further characterization of the role of apolipoproteins in the process of glaucoma has yet to be conducted.

Despite an abundance of literature grossly analyzing differences in the $\mathrm{AH}$ between patients with and without POAG [3, 10, 12, 27], to our knowledge, studies evaluating the influence of demographics are limited. In addition, studies analyzing gender and race-specific differences in the $\mathrm{AH}$ proteome did not examine different disease states $[2,15]$. Therefore, our study extends knowledge to identify how the interaction between demographic characteristics and POAG affects apolipoprotein levels in human $\mathrm{AH}$.

Our study possesses multiple strengths, including a large sample set and utilization of one of the latest LCMS/MS technologiesy for identification of proteins from small volume samples $[57,58]$. One of the limitations of this study is lack of quantification of the lipid content in human $\mathrm{AH}$. Other investigations have reported that the $\mathrm{AH}$ lipid profiles of patients with POAG are distinct from controls. Those studies have suggested the differential regulation of lipids such as 12,13-DiHOME and platelet activating factor, among others, is implicated in inflammatory processes $[59,60]$. Because lipids may be an essential component of the oxidative stress-related pathogenesis of POAG, further studies into the relationship between $\mathrm{AH}$ lipid content and apolipoprotein levels are required. Another limitation is our utilization of cataract patients as the control group. While these individuals have been traditionally employed in studies involving the $\mathrm{AH}[10-12,27]$, cataract formation is associated with alterations in multiple proteins, including $\beta$-crystallin and keratin proteins $[26,54]$. Accurate quantification of differences associated with disease states such as POAG would require the collection of control samples from healthy adults, an ethically unfeasible task.

\section{Conclusions}

In the present study, through utilization of a large sample set, we identified six apolipoproteins detected in all $\mathrm{AH}$ samples and one apolipoprotein detected in $57 \%$ of samples. Analysis of the relationships between these proteins and disease state, patient demographics, and clinical parameters of glaucomatous damage demonstrated multiple interactive effects. These differential associations emphasize the necessity of considering demographic factors including race and gender when analyzing a heterogeneous population. The elucidation of whether apolipoprotein alterations represent causative, degenerative, and/or reparative processes is important and warrants further study. Leveraging such results to treat glaucoma, detect its presence, or assess adequacy of treatment would be a boon to human vision.

\section{Supplementary Information}

The online version contains supplementary material available at https://doi. org/10.1186/s12944-021-01555-0.

\section{Additional file 1.}

\section{Acknowledgements}

Not applicable.

\section{Authors' contributions}

Conceptualization, P.A.P, S.K.K., S.S. and A.S.; Data curation, S.K.K. and G.J.; Formal analysis, S.K.K. and T.J.L.; Funding acquisition, A.S.; Methodology, S.K.K. and W.Z.; Project administration, A.S.; Resources, K.B., L.U., D.B., A.E., S.S. and A.S.; Software, T.J.L., A.S., and G.J.; Supervision, A.S.; Visualization, T.J.L.; Writing—original draft, P.A.P.; Writing—review \& editing, L.U., S.S., A.S., and G.J. All authors have read and agreed to the published version of the manuscript.

\section{Funding}

This work was funded by an NIH/NEl grant (R01-EY029728) awarded to Ashok Sharma.

\section{Availability of data and materials}

The datasets used in the current study are available as Supplemental Table-1.

\section{Declarations}

Ethics approval and consent to participate

The Institutional Review Board at Augusta University approved the study (IRB \#611480) and written informed consents were obtained from all study participants.

Consent for publication

Not applicable. 


\section{Competing interests}

The authors declare no conflict of interest.

\section{Author details}

${ }^{1}$ Center for Biotechnology and Genomic Medicine, Medical College of Georgia, Augusta University, 1120 15th Street, CA4094, Augusta, GA 30912, USA. ${ }^{2}$ Mass General Brigham, 215 First Street, Cambridge, MA 02142, USA. ${ }^{3}$ Department of Ophthalmology, Medical College of Georgia, Augusta University, Augusta, GA 30912, USA. ${ }^{4}$ Department of Population Health Sciences, Medical College of Georgia, Augusta University, Augusta, GA 30912, USA.

Received: 21 July 2021 Accepted: 13 September 2021 Published online: 03 October 2021

\section{References}

1. Grus FH, Joachim SC, Pfeiffer N. Proteomics in ocular fluids. Proteomics Clin Appl. 2007;1:876-88

2. Kodeboyina SK, Lee TJ, Churchwell L, Ulrich L, Bollinger K, Bogorad D, et al. The constitutive proteome of human aqueous humor and race specific alterations. Proteomes. 2020;8.

3. Chowdhury UR, Madden BJ, Charlesworth MC, Fautsch MP. Proteome analysis of human aqueous humor. Invest Ophthalmol Vis Sci. 2010;51:4921-31.

4. Murthy KR, Rajagopalan P, Pinto SM, Advani J, Murthy PR, Goel R, et al. Proteomics of human aqueous humor. OMICS. 2015;19:283-93.

5. Dominiczak MH, Caslake MJ. Apolipoproteins: metabolic role and clinical biochemistry applications. Ann Clin Biochem. 2011;48:498-515.

6. Ramasamy I. Recent advances in physiological lipoprotein metabolism. Clin Chem Lab Med. 2014;52:1695-727.

7. Sacca SC, Centofanti M, Izzotti A. New proteins as vascular biomarkers in primary open angle glaucomatous aqueous humor. Invest Ophthalmol Vis Sci. 2012;53:4242-53.

8. Kliuchnikova AA, Samokhina NI, llina IY, Karpov DS, Pyatnitskiy MA Kuznetsova KG, et al. Human aqueous humor proteome in cataract, glaucoma, and pseudoexfoliation syndrome. Proteomics. 2016;16:1938-46.

9. Bouhenni RA, Al Shahwan S, Morales J, Wakim BT, Chomyk AM, Alkuraya FS, et al. Identification of differentially expressed proteins in the aqueous humor of primary congenital glaucoma. Exp Eye Res. 2011;92:67-75.

10. Sharma S, Bollinger KE, Kodeboyina SK, Zhi W, Patton J, Bai S, et al. Proteomic alterations in aqueous humor from patients with primary open angle Glaucoma. Invest Ophthalmol Vis Sci. 2018;59:2635-43.

11. Baek JH, Lim D, Park KH, Chae JB, Jang H, Lee J, et al. Quantitative proteomic analysis of aqueous humor from patients with drusen and reticular pseudodrusen in age-related macular degeneration. BMC Ophthalmol. 2018:18:289.

12. Inoue T, Kawaji T, Tanihara H. Elevated levels of multiple biomarkers of Alzheimer's disease in the aqueous humor of eyes with open-angle Glaucoma. Invest Ophthalmol Vis Sci. 2013:54:5353-8.

13. Schaefer EJ, Zech LA, Jenkins LL, Bronzert TJ, Rubalcaba EA, Lindgren FT, et al. Human apolipoprotein A-I and A-II metabolism. J Lipid Res. 1982;23:850-62.

14. Anagnostis P, Stevenson JC, Crook D, Johnston DG, Godsland IF. Effects of gender, age and menopausal status on serum apolipoprotein concentrations. Clin Endocrinol. 2016:85:733-40.

15. Perumal N, Manicam C, Steinicke M, Funke S, Pfeiffer N, Grus FH. Characterization of the human aqueous humour proteome: a comparison of the genders. PLoS One. 2017;12:e0172481.

16. Salgarello $T$, Colotto A, Falsini B, Buzzonetti L, Cesari L, larossi G, et al. Correlation of pattern Electroretinogram with optic disc cup shape in ocular hypertension. Invest Ophthalmol Vis Sci. 1999:40:1989-97.

17. Apolipoproteins | HUGO Gene Nomenclature Committee [https://www. genenames.org/data/genegroup/\#!/group/405].

18. Mao $Y, X U$ Y, Lu L. The nonlinear association between apolipoprotein B to apolipoprotein A1 ratio and type 2 diabetes. Medicine (Baltimore). 2017:96:e5834.

19. Contois JH, McConnell JP, Sethi AA, Csako G, Devaraj S, Hoefner DM, et al. Vascular diseases division working group on best $\mathrm{P}$ : apolipoprotein $\mathrm{B}$ and cardiovascular disease risk: position statement from the AACC Lipoproteins and vascular diseases division working group on best practices. Clin Chem. 2009:55:407-19.
20. Mendivil CO, Rimm EB, Furtado J, Chiuve SE, Sacks FM. Low-density lipoproteins containing apolipoprotein C-III and the risk of coronary heart disease. Circulation. 2011;124:2065-72.

21. Kim J, Basak JM, Holtzman DM. The role of apolipoprotein E in Alzheimer's disease. Neuron. 2009;63:287-303.

22. Giau W, Bagyinszky E, An SS, Kim SY. Role of apolipoprotein E in neurodegenerative diseases. Neuropsychiatr Dis Treat. 2015;11:1723-37.

23. Najm $\mathrm{R}$, Jones EA, Huang $\mathrm{Y}$. Apolipoprotein E4, inhibitory network dysfunction, and Alzheimer's disease. Mol Neurodegener. 2019;14:24.

24. Williams T, Borchelt DR, Chakrabarty P. Therapeutic approaches targeting apolipoprotein E function in Alzheimer's disease. Mol Neurodegener. 2020;15:8.

25. Maiti TK, Konar S, Bir S, Kalakoti P, Bollam P, Nanda A. Role of apolipoprotein E polymorphism as a prognostic marker in traumatic brain injury and neurodegenerative disease: a critical review. Neurosurg Focus. 2015;39:E3.

26. Xiang M, Zhang X, Li Q, Wang H, Zhang Z, Han Z, et al. Identification of proteins in the aqueous humor associated with cataract development using iTRAQ methodology. Mol Med Rep. 2017; 15:3111-20.

27. Kaeslin MA, Killer HE, Fuhrer CA, Zeleny N, Huber AR, Neutzner A. Changes to the aqueous humor proteome during Glaucoma. PLoS One. 2016;11: e0165314.

28. Liu X, Liu X, Wang Y, Sun H, Guo Z, Tang X, et al. Proteome characterization of glaucoma aqueous humour. Mol Cell Proteomics. 2021;100117.

29. Buch $H$, Vinding $T$, La Cour M, Jensen GB, Prause JU, Nielsen NV. Risk factors for age-related maculopathy in a 14-year follow-up study: the Copenhagen City eye study. Acta Ophthalmol Scand. 2005;83:409-18.

30. Kawai S, Nakajima T, Hokari S, Komoda T, Kawai K. Apolipoprotein A-I concentration in tears in diabetic retinopathy. Ann Clin Biochem. 2002; 39:56-61.

31. Quaranta L, Bruttini C, Micheletti E, Konstas AGP, Michelessi M, Oddone F, et al. Glaucoma and neuroinflammation: An overview. Surv Ophthalmol. 2021;66:693-713.

32. Sun Z, Larson IA, Ordovas JM, Barnard JR, Schaefer EJ. Effects of age, gender and lifestyle factors on plasma apolipoprotein A-IV concentrations. Atherosclerosis. 2000;151:381-8.

33. Foster PJ, Broadway DC, Hayat S, Luben R, Dalzell N, Bingham S, et al. Refractive error, axial length and anterior chamber depth of the eye in British adults: the EPIC-Norfolk eye study. Br J Ophthalmol. 2010;94:827-30.

34. Hashemi $H$, Khabazkhoob M, Miraftab M, Emamian MH, Shariati M, Abdolahinia T, et al. The distribution of axial length, anterior chamber depth, lens thickness, and vitreous chamber depth in an adult population of Shahroud, Iran. BMC Ophthalmol. 2012;12:50.

35. Chen H, Lin H, Lin Z, Chen J, Chen W. Distribution of axial length, anterior chamber depth, and corneal curvature in an aged population in South China. BMC Ophthalmol. 2016;16:47.

36. Zhang N, Wang J, Li Y, Jiang B. Prevalence of primary open angle glaucoma in the last 20 years: a meta-analysis and systematic review. Sci Rep. 2021;11: 13762.

37. Tehrani S. Gender difference in the pathophysiology and treatment of Glaucoma. Curr Eye Res. 2015:40:191-200.

38. Prokai-Tatrai K, Xin H, Nguyen V, Szarka S, Blazics B, Prokai L, et al. 17ßestradiol eye drops protect the retinal ganglion cell layer and preserve visual function in an in vivo model of glaucoma. Mol Pharm. 2013;10: 3253-61.

39. Zhou X, Li F, Ge J, Sarkisian SR Jr, Tomita H, Zaharia A, et al. Retinal ganglion cell protection by 17-beta-estradiol in a mouse model of inherited glaucoma. Dev Neurobiol. 2007;67:603-16.

40. Zalewski A, Cecchini EL, Deroo BJ. Expression of extracellular matrix components is disrupted in the immature and adult estrogen receptor $\beta$ null mouse ovary. PLoS One. 2012;7:e29937.

41. Friedman DS, Wolfs RC, O'Colmain BJ, Klein BE, Taylor HR, West $\mathrm{S}$, et al. Prevalence of open-angle glaucoma among adults in the United States. Arch Ophthalmol. 2004;122:532-8.

42. Broman AT, Quigley HA, West SK, Katz J, Munoz B, Bandeen-Roche K, et al. Estimating the rate of progressive visual field damage in those with openangle glaucoma, from cross-sectional data. Invest Ophthalmol Vis Sci. 2008; 49:66-76.

43. Szaflik JP, Nowak A, Rozpędek W, Siwak M, Szymanek K, Szaflik M, et al. Association of apolipoprotein $\mathrm{E}$ with a risk of primary open-angle glaucoma. Acta Ophthalmol. 2017:95 
44. Reindl M, Knipping G, Wicher I, Dilitz E, Egg R, Deisenhammer F, et al. Increased intrathecal production of apolipoprotein D in multiple sclerosis. J Neuroimmunol. 2001;119:327-32.

45. Terrisse L, Poirier J, Bertrand P, Merched A, Visvikis S, Siest G, et al. Increased levels of apolipoprotein $D$ in cerebrospinal fluid and hippocampus of Alzheimer's patients. J Neurochem. 1998;71:1643-50.

46. Zenkel M, Pöschl E, von der Mark K, Hofmann-Rummelt C, Naumann GO, Kruse $\mathrm{FE}$, et al. Differential gene expression in pseudoexfoliation syndrome. Invest Ophthalmol Vis Sci. 2005;46:3742-52.

47. Thomas EA, Copolov DL, Sutcliffe JG. From pharmacotherapy to pathophysiology: emerging mechanisms of apolipoprotein D in psychiatric disorders. Curr Mol Med. 2003;3:408-18.

48. Sutcliffe JG, Thomas EA. The neurobiology of apolipoproteins in psychiatric disorders. Mol Neurobiol. 2002;26:369-88.

49. Kodeboyina SK, Lee TJ, Bollinger K, Ulrich L, Bogorad D, Estes A, et al. Aqueous humor proteomic alterations associated with visual field index parameters in Glaucoma patients: a pilot study. J Clin Med. 2021:10:1180

50. Goodrum JF, Earnhardt T, Goines N, Bouldin TW. Fate of myelin lipids during degeneration and regeneration of peripheral nerve: an autoradiographic study. J Neurosci. 1994;14:357-67.

51. Goodrum JF, Weaver JE, Goines ND, Bouldin TW. Fatty acids from degenerating myelin lipids are conserved and reutilized for myelin synthesis during regeneration in peripheral nerve. J Neurochem. 1995;65:1752-9.

52. Rickhag M, Deierborg T, Patel S, Ruscher K, Wieloch T. Apolipoprotein D is elevated in oligodendrocytes in the peri-infarct region after experimental stroke: influence of enriched environment. J Cereb Blood Flow Metab. 2008; 28:551-62.

53. Cehofski L, Kojima K, Terao N, Kitazawa K, Thineshkumar S, Grauslund J, et al. Aqueous fibronectin correlates with severity of macular edema and visual acuity in patients with branch retinal vein occlusion: a proteome study. Invest Ophthalmol Vis Sci. 2020;61:6-6.

54. Ji Y, Rong $X$, Ye H, Zhang K, Lu Y. Proteomic analysis of aqueous humor proteins associated with cataract development. Clin Biochem. 2015:48:1304-9.

55. Ouchi M, West K, Crabb JW, Kinoshita S, Kamei M. Proteomic analysis of vitreous from diabetic macular edema. Exp Eye Res. 2005;81:176-82.

56. Simó R, Higuera M, García-Ramírez M, Canals F, García-Arumí J, Hernández C. Elevation of apolipoprotein $\mathrm{A}-\mathrm{I}$ and apolipoprotein $\mathrm{H}$ levels in the vitreous fluid and overexpression in the retina of diabetic patients. Arch Ophthalmol. 2008;126:1076-81.

57. Baldwin MA. Protein identification by mass spectrometry: issues to be considered. Mol Cell Proteomics. 2004;3:1-9.

58. Di Girolamo F, Lante I, Muraca M, Putignani L. The role of mass spectrometry in the "Omics" era. Curr Org Chem. 2013;17:2891-905.

59. Azbukina NV, Chistyakov DV, Goriainov SV, Kotelin VI, Fedoseeva EV, Petrov SY, et al. Targeted Lipidomic analysis of aqueous humor reveals signaling lipid-mediated pathways in primary open-angle Glaucoma. Biology (Basel). 2021;10.

60. Cabrerizo J, Urcola JA, Vecino E. Changes in the Lipidomic profile of aqueous humor in open-angle Glaucoma. J Glaucoma. 2017;26:349-55.

\section{Publisher's Note}

Springer Nature remains neutral with regard to jurisdictional claims in published maps and institutional affiliations.

Ready to submit your research? Choose BMC and benefit from:

- fast, convenient online submission

- thorough peer review by experienced researchers in your field

- rapid publication on acceptance

- support for research data, including large and complex data types

- gold Open Access which fosters wider collaboration and increased citations

- maximum visibility for your research: over $100 \mathrm{M}$ website views per year

At $\mathrm{BMC}$, research is always in progress.

Learn more biomedcentral.com/submissions 